\title{
Analysis of Conversion Losses in Grid Connected Small Wind Turbine Systems
}

\author{
Md. Arifujjaman*, M.T. Iqbal and J. E. Quaicoe \\ Faculty of Engineering and Applied Science, Memorial University of Newfoundland, St. John's, NL, Canada AlB3X5
}

\begin{abstract}
This paper presents a comprehensive conversion loss analysis of the Power Conditioning System (PCS) for a grid connected Permanent Magnet Generator (PMG) and a Wound Rotor Induction Generator (WRIG) based small wind turbine system. The main focus of the loss analysis is the conduction and switching losses in the semiconductor devices and PCS. The analysis reveals that the WRIG based system with a slip variation up to $15 \%$ could provide higher efficiency than the PMG based system. In particular, a significant improvement is observed at the low wind speed regime in case of the WRIG based system than the PMG based system. Finally, this paper concludes that the WRIG based system could be an optimum alternative system for the small wind turbine industry.
\end{abstract}

\section{INTRODUCTION}

Wind power is presently a cost effective renewable technology and provides a continuously growing contribution to climate change goals, energy diversity and security. Net metering of grid connected small wind turbine systems offers users a reasonable payback and is an attractive feature of such systems. Nevertheless, the Canadian small wind turbine manufacturing capacity is well suited to the farms \& commercial market and to the northern communities market, while a considerable lack in development exist for on grid connected residential market [1]. The reasons for shadowy existence of on grid residential market are manifold: high cost, a lack of technological maturity, insufficient testing, a complex market with a large number of manufacturers, and lack of proper standards for the small wind turbine. Besides this, the most important reason is yet to be mentioned, i.e., an overall perspective on contemporary wind turbine concepts, reliability and performance of power conditioning systems over the years. Different power conditioning system could exhibit different conversion losses and efficiency, which should be analyzed carefully before installation of a small wind energy conversion system.

Grid connected Permanent Magnet Generator (PMG) based Small Wind Turbines (SWTs) typically employ a 3phase bridge rectifier and a boost converter stage prior to a grid connected inverter [2-8]. The boost converter boosts the voltage of the dc link as required by the inverter. In contrast to the most common PMG based system as presented in Fig. (1), a WRIG based SWT system can be considered as an alternative. Such system is typically used with large wind turbines. The PCS of such an arrangement is composed of a 3-phase bridge rectifier, a chopper and an external resistance as presented in Fig. (2). This system requires a costly induction generator with slip rings but the PCS cost reduce

*Address correspondence to this author at the Graduate Student, PO Box100, Faculty of Engineering and Applied Science; Memorial University of Newfoundland, St. John's, NL, Canada A1B3X5, Canada;

Fax/Tel: (709)-737 2573; E-mails: mda04@mun.ca; sumon326@yahoo.com dramatically as the rectifiers and switches will cope with the $20 \%-30 \%$ of the rated power through slip rings. Different grid connected small wind turbine systems are compared mainly regarding the efficiency of one system over the other. This paper introduces the loss analysis and afterwards the efficiency of the PCS for a PMG and WRIG based system. The loss analysis is important when comparing different systems PCS because the losses reduce the average power produced by the wind turbine and subsequently reduces the income.

The analysis of PCS losses, which accordingly impact the efficiency of wind turbine system have been studied by numerous literatures in the past [8-20]. There are principally two approaches of loss analysis of the PCS, which are briefly discussed here. The first approach is the development of a non linear loss model of the PCS based on the on-state current of the semiconductor devices [8-11]. Because it is easy to relate the on-state current of the PCS and operating conditions of the wind turbine, it has a relatively simple calculation and is a good choice while differentiating between systems. On the other hand, this approach is unable to reflect the switching losses of the semiconductor devices, which could be a dominant factor during the high switching state. Indeed, switching losses have been considered [12], however excluding the dependency on the actual commutation voltage or current during conduction loss analysis could lead to an ambiguous result. The second one is a curve fitting approach, where the simulation is carried out by considering an ideal switch and then combines the manufacturers' published power loss data by using a curve fitting technique. Theoretically, this approach offers the optimal solution as it considers both conduction and switching losses of the semiconductor devices. However, one of the main disadvantages is recognizable; it is hard to rely on the manufacturers' published data, which can lead to a pessimistic loss analysis of the system [13-17]. There have been numerous other methods for analysis of the PCS losses of wind turbines. Miaosen et al. [2] have presented the concept of switching device power loss of the PCS in wind turbine. The maximum device rating has been considered in the loss analysis. The calculation of 


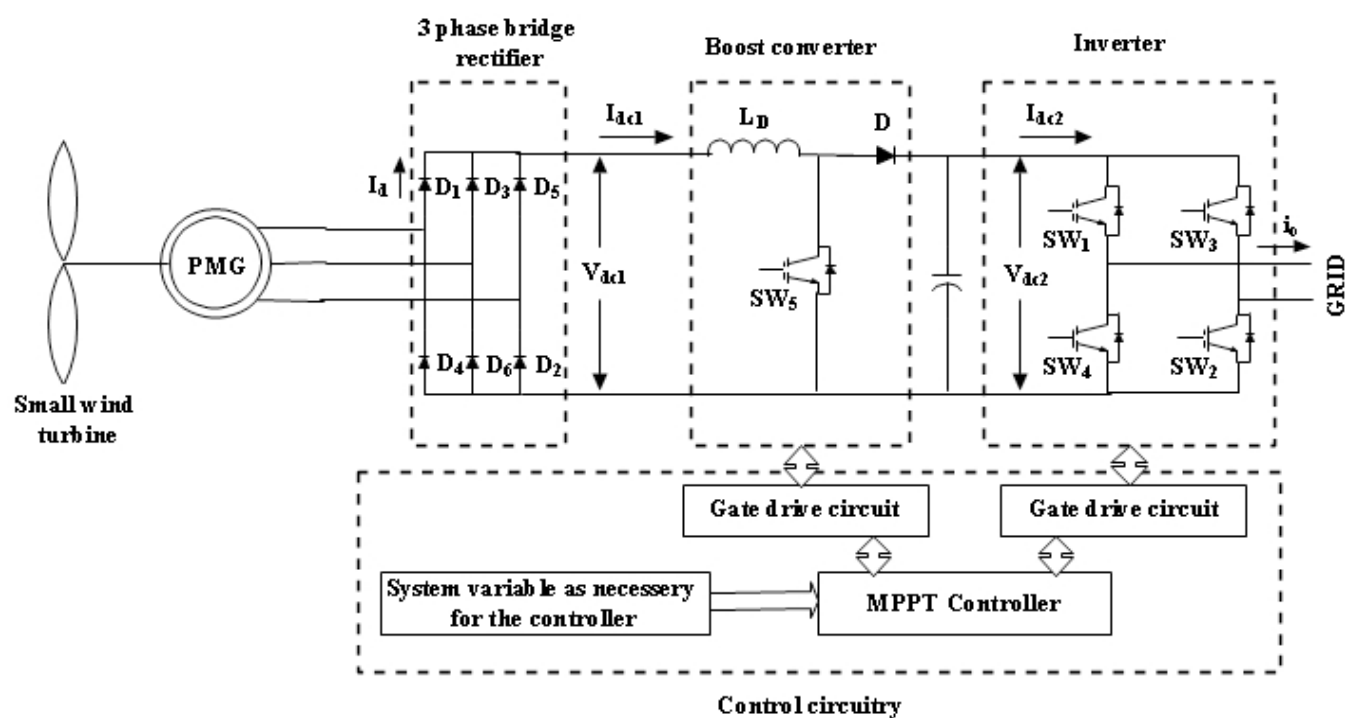

Fig. (1). A PMG based topology for small wind turbine system.

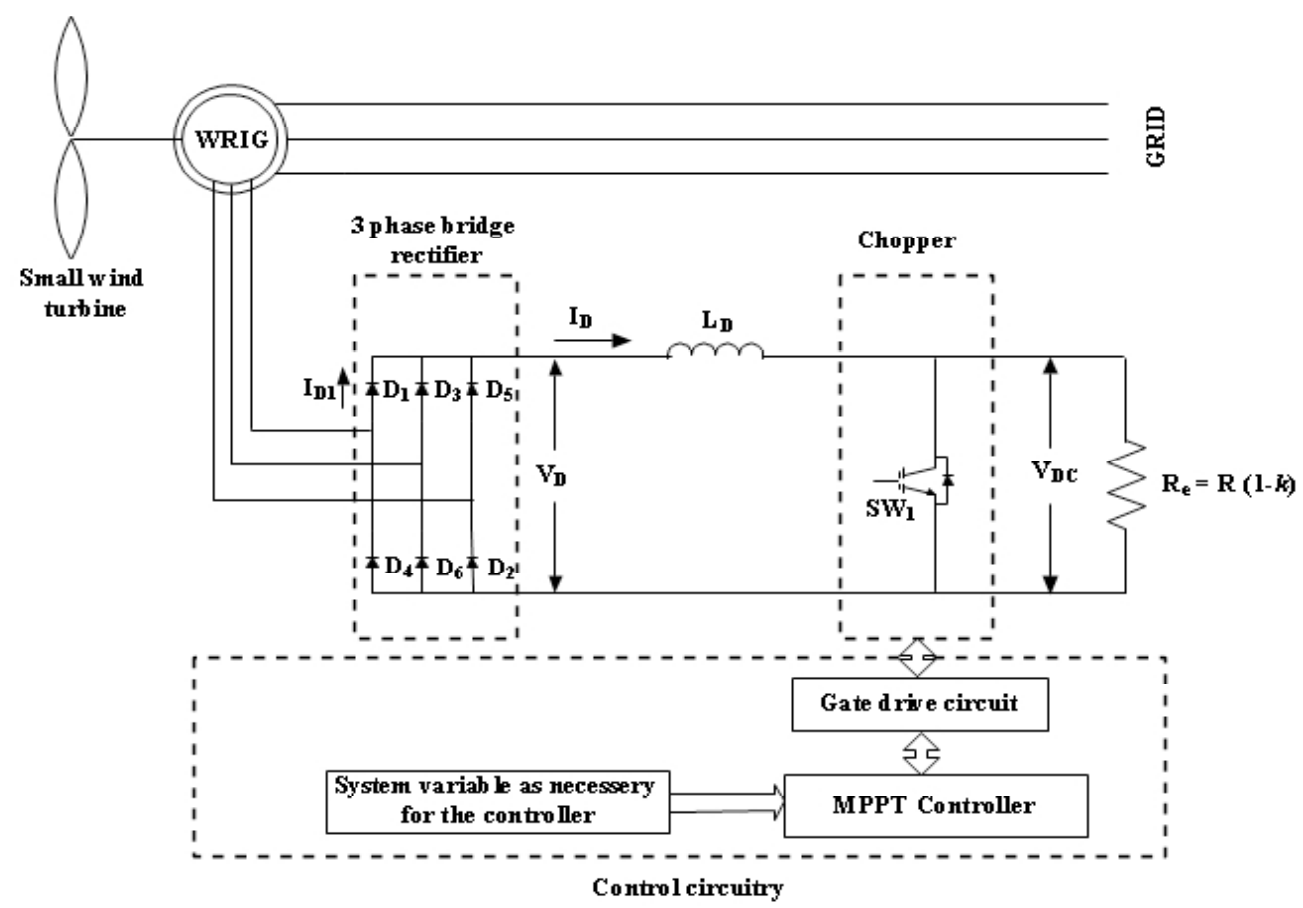

Fig. (2). A WRIG based topology for small wind turbine system.

the switching losses has not been investigated. The switching losses have been considered in [18-20] using the same concept, i.e., maximum device rating, however, the calculation of conduction losses lacks the valid justification as the actual commutation voltage or current is neglected.

Based on the above discussions, it can be asserted that most of the attempts for the PCS loss analysis have been developed based on several assumptions and often neglected a fraction of the entire PCS power loss. This discrepancy could affect the preference of an optimum small grid connected wind turbine system that is in a great need for high penetration of the wind power. As a consequence, this research aims at advancing the use of grid connected small wind turbine by analyzing a comprehensive conversion loss analysis within the PCS. The loss analysis presented in this investigation focuses on the conduction and switching loss of the semiconductors and total loss in PCS. The variation of duty cycle of the boost converter for a PMG-based system is considered as a maximum value. This is due to the fact that the semiconductor devices will transmit the maximum indirect power, i.e., maximum stress on the devices thus resembles the worst case scenario [21]. The dependence on the actual commutation voltage and current is also considered by a linear approximation. Finally, the conversion losses with the variation of wind speed of the PMG and WRIG based small wind turbine systems have been investigated for an optimum grid connected system. 


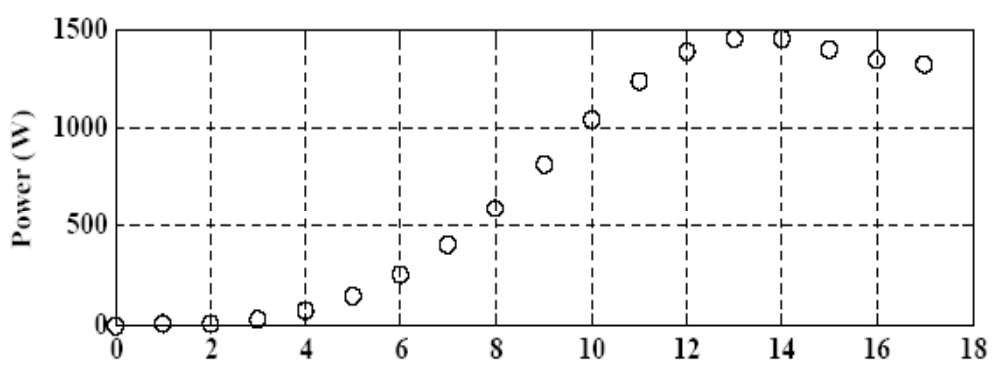

(a) Wind speed $(\mathrm{m} / \mathrm{s})$

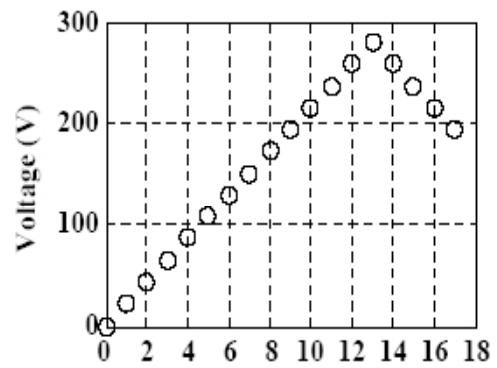

(b) Wind speed $(\mathrm{m} / \mathrm{s})$

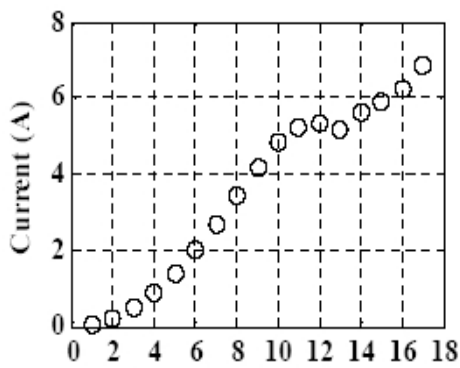

(c) Wind speed $(\mathrm{m} / \mathrm{s})$

Fig. (3). Characteristics of the PMG based SWT at the output of the rectifier a) Power, b) Voltage, c) Current.

This paper is organized as follows: The operating conditions of such small wind turbine are discussed in the third section, and the fourth section contains the mathematical formulation for loss analysis. Results and discussions are presented and discussed in the fifth section and finally, the findings of the investigations are highlighted in the conclusions.

\section{OPERATING CONDITIONS OF WIND TURBINES}

The operating conditions for a PMG and a WRIG based SWT system must be known for the investigation of losses occurred in the PCS. For a PMG based SWT, the level of the DC output voltage at the boost converter remains constant while output from the rectifier depends on the wind speed, the generator characteristics and the control strategy. In this research it has been assumed that the turbine is operated as a variable speed wind turbine. This signifies that for low wind speeds to high wind speed, the wind turbine maintains a constant tip-speed-ratio to ensure the maximum power production. In addition, when the wind speed increases, the turbine yaw to an angle, $\delta$ along its horizontal axis because of the furling action. In Fig. (3a) the output power from the wind turbine is presented as a function of wind speed. This theoretical maximum power of the wind turbine serves as the dynamic power reference for the both topologies. For the studied turbine, the cut-in wind speed is about $2 \mathrm{~m} / \mathrm{s}$ and the rated rotational speed is reaches at a rated wind speed of 13 $\mathrm{m} / \mathrm{s}$, while the cut out wind speed is $17 \mathrm{~m} / \mathrm{s}$. Since the PMG is connected to a diode rectifier (Fig. 1), it is assumed that the output voltage of the rectifier is proportional to the rotational speed of the generator. The voltage is assumed to be $40 \mathrm{~V}$ at $2 \mathrm{~m} / \mathrm{s}$ wind speed and $280 \mathrm{~V}$ at $13 \mathrm{~m} / \mathrm{s}$ wind speed as shown in the Fig. (3b). Corresponding current curve at the rectifier output is given by Fig. (3c). Drop in turbine speed and output voltage above $13 \mathrm{~m} / \mathrm{s}$ wind speed is due to the automatic furling of the wind turbine. Furling angle in- creases with the wind speed above $13 \mathrm{~m} / \mathrm{s}$ leading to a reduced output power.

\section{MATHEMATICAL FORMULATION}

A mathematical formulation of the conversion losses is required in order to compare two topologies. The brief formulation for the conversion loss calculation of a PMG based topology is derived in the previous paper [22], however, for convenience, a short synopsis is presented in the following section followed by the mathematical formulation for loss calculation of a WRIG based topology.

\subsection{Mathematical Formulation for a PMG based SWT}

The conduction and switching losses for a 3 phase diode bridge rectifier can be expressed by (1) and (2) respectively, while the total losses for a module of 6 diodes is given by (3) [22]:

$$
\begin{aligned}
& P_{c d, d}{ }^{D B}=V_{f 0} I_{d} \\
& P_{s w, d}{ }^{D B}=f_{W T} E_{S R} \cdot \frac{V_{d c 1}}{V_{r e f, d}} \cdot \frac{I_{d c 1}}{I_{r e f, d}} \\
& P_{t, d}{ }^{D B}=6 P_{c d, d}{ }^{\mathrm{DB}}+6 P_{s w, d}{ }^{D B}=P_{c d t, d}{ }^{D B}+P_{s w t, D B}{ }^{D B}
\end{aligned}
$$

In a similar manner, considering duty cycle, $d$ the conduction and switching losses for the diode and IGBT of the boost converter is given by (4), (5) and (6), (7) respectively, and their total losses is expressed by (8) [22]:

$$
\begin{aligned}
& P_{c d, d}^{B C}=I_{d c 1}\left(V_{f 0}+r_{d} I_{d c 1}\right) \cdot(1-d) \\
& P_{c d, I G B T}^{B C}=I_{d c 1}\left(V_{c e 0}+r_{c e} I_{d c 1}\right) \cdot d \\
& P_{s w, d}^{B C}=f_{s w} E_{S R} \cdot \frac{V_{d c 2}}{V_{r e f, d}} \cdot \frac{I_{d c 1}}{I_{r e f, d}}
\end{aligned}
$$




$$
\begin{gathered}
P_{s w, I G B T}^{B C}=f_{s w}\left(E_{O N}+E_{O F F}\right) \cdot \frac{V_{d c 2}}{V_{r e f, I G B T}} \cdot \frac{I_{d c 1}}{I_{r e f, I G B T}} \\
P_{t,(d+I G B T)}^{B C}=\left(P_{c d, d}{ }^{B C}+P_{s w, d}{ }^{B C}\right)+\left(P_{c d, I G B T}{ }^{B C}+P_{s w, I G B T}{ }^{B C}\right)
\end{gathered}
$$

Most of the grid connected SWT systems use a single phase inverter. Ignoring the snubber circuits, the inverter power stage consists of 4 switches and 4 anti parallel diodes as presented by Fig. (1). Considering phase angle, $\theta$ between the grid voltage and current and modulation index, $M$, the conduction and switching loss of a diode and IGBT of the inverter can be expressed by (9), (10) and (11), (12) respectively [22]:

$$
\begin{aligned}
& P_{c d 1, d}^{I N V}=\left(\frac{1}{8}-\frac{M}{3 \pi} \cos \theta\right) r_{d} I_{o m}{ }^{2}+\left(\frac{1}{2}+\frac{M}{8} \cos \theta\right) V_{f 0} I_{o m} \\
& P_{c d 1, I G B T}^{I N V}=\left(\frac{1}{8}+\frac{M}{3 \pi} \cos \theta\right) r_{c e} I_{o m}{ }^{2}+\left(\frac{1}{2}+\frac{M}{8} \cos \theta\right) V_{c e 0} I_{o m} \\
& P_{s w 1, d}^{I N V}=\frac{1}{\pi} f_{s w} E_{S R} \frac{V_{d c 2}}{V_{r e f, d}} \frac{I_{o}}{I_{r e f, d}} \\
& P_{s w 1, I G B T}^{I N V}=\frac{1}{\pi} f_{s w}\left[E_{\text {ON }}+E_{\text {OFF }}\right] \frac{V_{d c 2}}{V_{r e f, I G B T}} \frac{I_{o}}{I_{r e f, I G B T}}
\end{aligned}
$$

Adding up (9), (10), (11) and (12) provides the total power loss of the inverter circuit and is expressed by (13) while the total losses of the conversion stage of the PMG based SWT is presented by (14):

$$
\begin{aligned}
& P_{t,(d+I G B T)}^{I N V}=P_{c d, d}{ }^{I N V}+P_{c d, I G B T}{ }^{I N V}+P_{s w, d}^{I N V}+P_{s w, I G B T}{ }^{I N V} \\
& P_{t}^{P M G}=P_{t, d}{ }^{D B}+P_{t,(d+I G B T)}^{B C}+P_{t,(d+I G B T)}^{I N V}
\end{aligned}
$$

where, $P_{c d, d}^{I N V}=4 P_{c d 1, d}^{I N V}$ and $P_{c d, I G B T}^{I N V}=4 P_{c d 1, I G B T}^{I N V}$ and $P_{s w, d}{ }^{I N V}=4 P_{s w 1, I G B T}{ }^{I N V}$ and $P_{s w, I G B T}{ }^{I N V}=4 P_{s w 1, I G B T}{ }^{I N V}$

\subsection{Mathematical Formulation for a WRIG based SWT}

In a WRIG, a variable resistor in the rotor circuit effectively controls the rotor current as well as the speed of the wind turbine. The approximate equivalent circuits of a 3phase WRIG in conjunction with the diode rectifier and chopper is shown in Fig. (4), which can be obtained by assuming that the stator and rotor leakage impedances are neglected as compared to inductor $L_{D}$. The stator voltage $V_{1}$, referred to the rotor circuit, results in a slip frequency voltage, $s E_{2}$. The output voltage, $V_{D}$ of the rectifier can be expressed as [23].
$V_{D}=\left(3 \sqrt{6} s \cdot a \cdot V_{1}\right) / \pi$

where, $s$ is the slip and $a$ represents the ratio of rotor to stator turn.

The losses in the external rotor resistor and chopper are given by:

$P_{l, e x}{ }^{R}=V_{D} I_{D}$

where, $V_{D}$ and $I_{D}$ is the rectified output voltage and current at the rotor respectively.

The sum of the losses in the rectifier, external rotor resistor and chopper is equal to the slip power entering to the rotor. Equating the losses to the slip power and assuming that $r_{d 1} \ll R$, results in:

$$
I_{D}=\frac{s P_{S}}{\left[2 V_{f 0}+\frac{6 f_{W T} E_{S R} V_{D}}{V_{r e f 1} I_{r e f 1}}+V_{D}\right]}
$$

where, $P_{s}$ is the power delivered by the stator of the generator and represents the maximum captured aerodynamic power of the wind turbine.

The total of the losses of the 3-phase diode bridge rectifier for the WRIG based SWT is the sum of conduction and switching losses and is given by:

$$
P_{t, d}^{W R I G}=P_{c d 2, d}^{D B}+P_{s w 2, d}^{D B}=2 V_{f 0} I_{D}+\frac{6 f_{W T} E_{S R} V_{D} I_{D}}{V_{r e f 1} I_{r e f 1}}
$$

The losses in the slip ring consist of electrical and friction losses. The electrical losses are the sum of the resistive losses in the brushes and slip ring and the loss originated from the contact voltage drop between the slip ring and the brush. While, the friction losses are dependent on various factors, for instance, area of the brush, number of brushes, friction coefficient, spring force and the speed of the slip ring. In addition, the electrical and friction losses are also dependent on the brush material. The electrical and friction loss due to the rotation of the rotor is described in (19) and (20) respectively [24]:

$$
\begin{aligned}
& P_{\text {elec,slipring }}{ }^{W R I G}=K_{\omega} \omega \\
& P_{\text {fric,slipring }}{ }^{W R I G}=K_{\delta} \omega
\end{aligned}
$$

where, $K_{\omega}$ and $K_{\delta}$ are the constant that depends on the contact voltage drop and friction coefficient respectively. Thus the total losses of the WRIG can be expressed by (21).

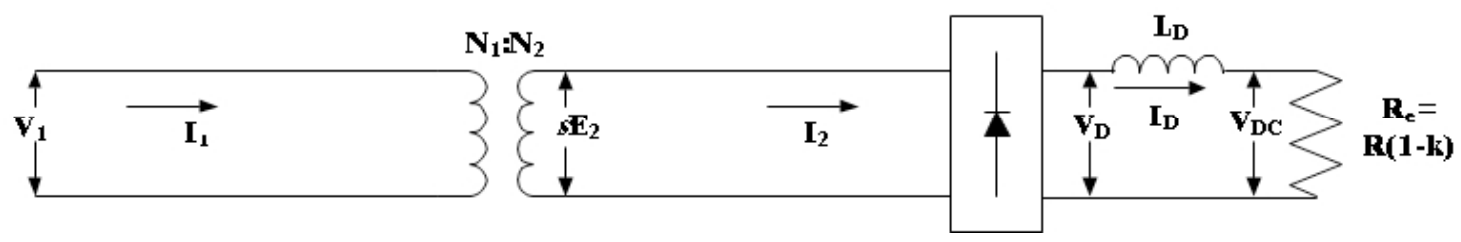

Fig. (4). Approximate equivalent circuit of a WRIG. 


$$
P_{t}^{W R I G}=P_{t, d}{ }^{W R I G}+P_{t, \text { ext }}{ }^{\text {WRIG }}+P_{\text {elec,slipring }}{ }^{\text {WRIG }}+P_{\text {fric,slipring }}{ }^{\text {WRIG }}
$$

\section{RESULTS AND DISCUSSIONS}

The analytical calculations illustrated in the above sections were carried out to determine the total conversion losses occurred in two SWT topologies under varying wind speed conditions. The rated power for the wind turbine is assumed to be $1.5 \mathrm{~kW}$. The inverter switching frequency is considered as $20 \mathrm{kHz}$ and to investigate the worst-case scenario of the power loss in this numerical simulation study, the modulation index is assumed unity and load current is assumed in phase with the output voltage. The inverter operates in the linear modulation region while over modulation and under modulation region is excluded from this study. Another pre-assumption for the simulation study was that the inductance used in the boost converter topology is ideal. The thermal model of the power conditioning system is also neglected provided that the heat sink is adequate enough to maintain the semiconductors proper working. Power wasted in the power supplies of the inverter and boost converter control circuits is also ignored (It may be between 10-20W).

The conduction and switching losses in the 3 phase diode bridge rectifier of PMG based system are presented in Fig. (5) followed by the losses in IGBT and diode of the boost converter in Fig. (6) as a function of wind speed. Fig. (7) exposes the conduction and switching losses of the IGBT and anti parallel diodes of the inverter (Fig. 1) for a similar wind variation.
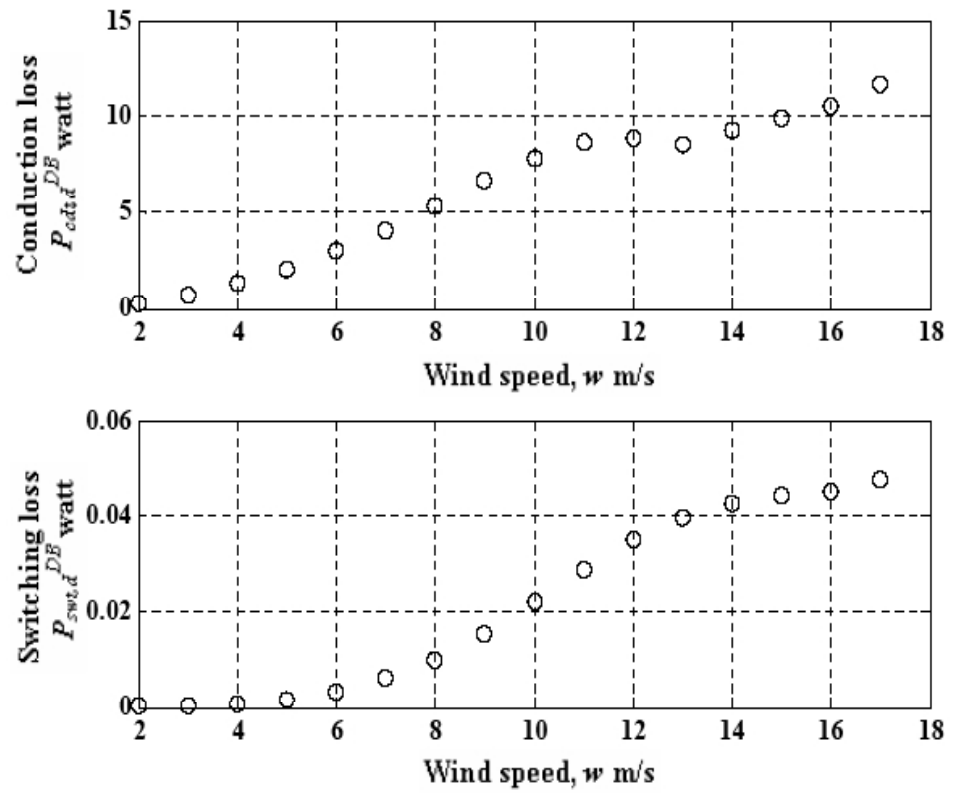

Fig. (5). Conduction and switching loss of the 3-phase diode bridge rectifier.
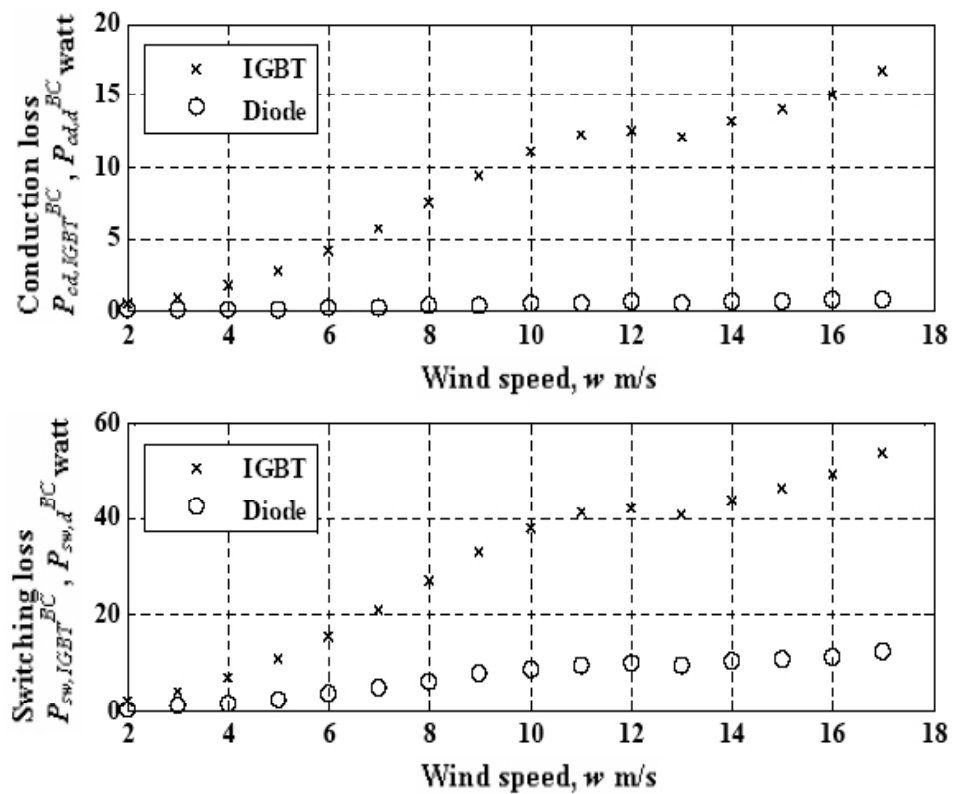

Fig. (6). Conduction and switching loss of the diode and IGBT of the boost converter. 

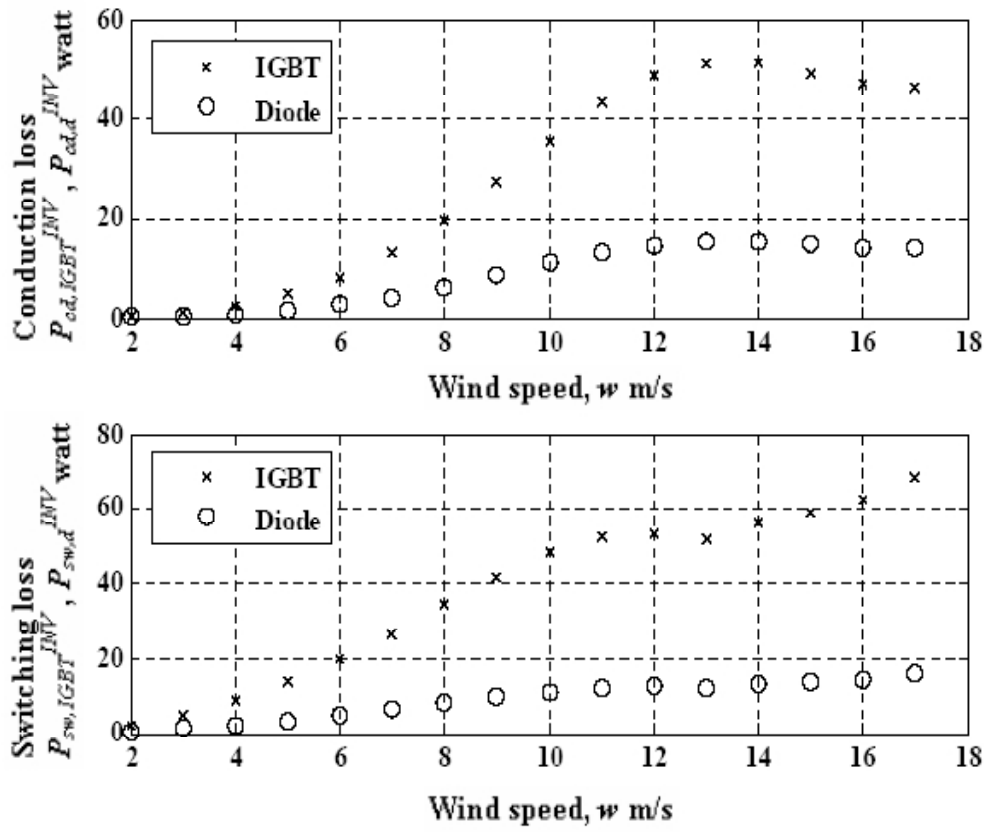

Fig. (7). Conduction and switching loss of the diodes and IGBTs of the inverter.
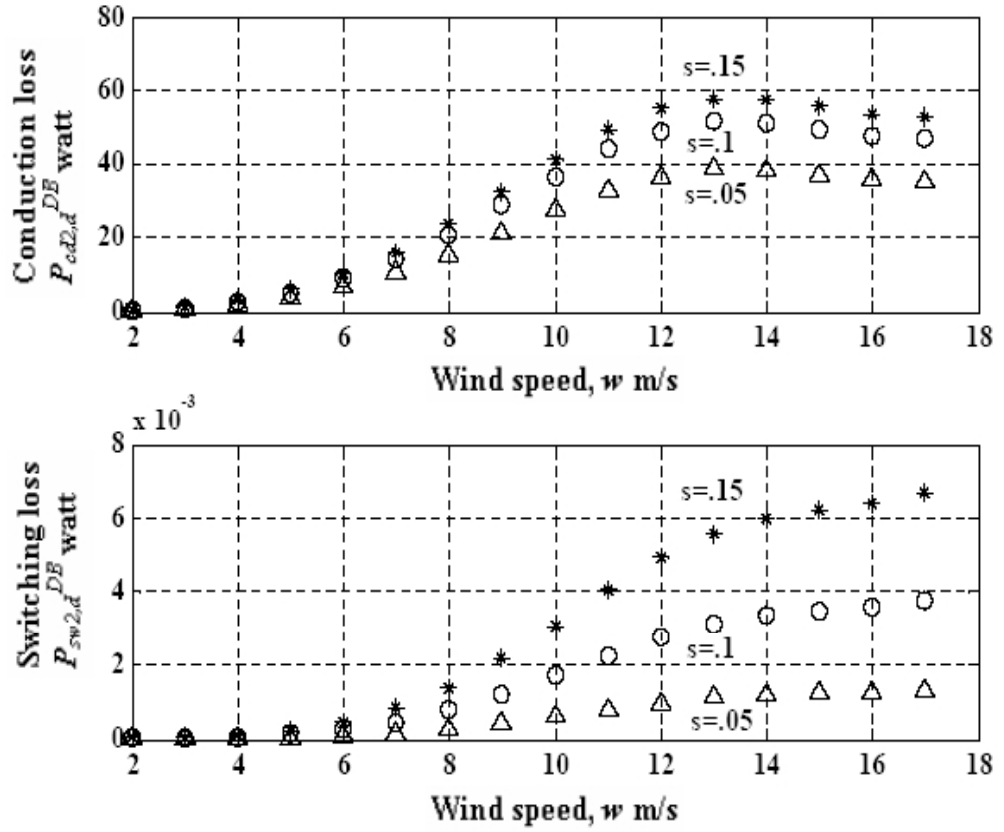

Fig. (8). Conduction and switching losses of the 3 phase diode bridge rectifier for a WRIG based system.

Losses were analyzed for the WRIG based system subjected to same conditions as the PMG based system. Higher values of slip results in high power loss and vice versa, while a low variation of slip resembles almost a constant speed system. A slip variation of $15 \%(5 \%, 10 \%$ and $15 \%)$ is investigated and the conduction and switching loss for varying wind speed of the 3 phase bridge rectifier in the rotor circuit of WRIG are presented in Fig. (8). A WRIG based system suffers from the dilemmas of power loss in the external rotor resistor and it is presented in Fig. (9) for a variation of slip as well as wind speed. The variation of electrical loss with the variation of wind speed for three different slip values is presented in Fig. (10). The frictional loss of a slip ring strongly dependent on speed of rotation and has a linear dependency with the speed of rotation and presented in Fig. (11) with a variable wind speed and slip.

The variation in total power losses in PCS for a PMG and WRIG based system is presented in Fig. (12) and Fig. (13) respectively. The conduction and switching loss results for a PMG based system discloses that the power loss is more for a low wind speed $(12 \mathrm{~m} / \mathrm{s})$ rather for a high wind speed (13 $\mathrm{m} / \mathrm{s}$ ) and is due to the furling action. The furling angle varies abruptly from $10 \mathrm{~m} / \mathrm{s}$ to $14 \mathrm{~m} / \mathrm{s}$ and changes are insignifi- 


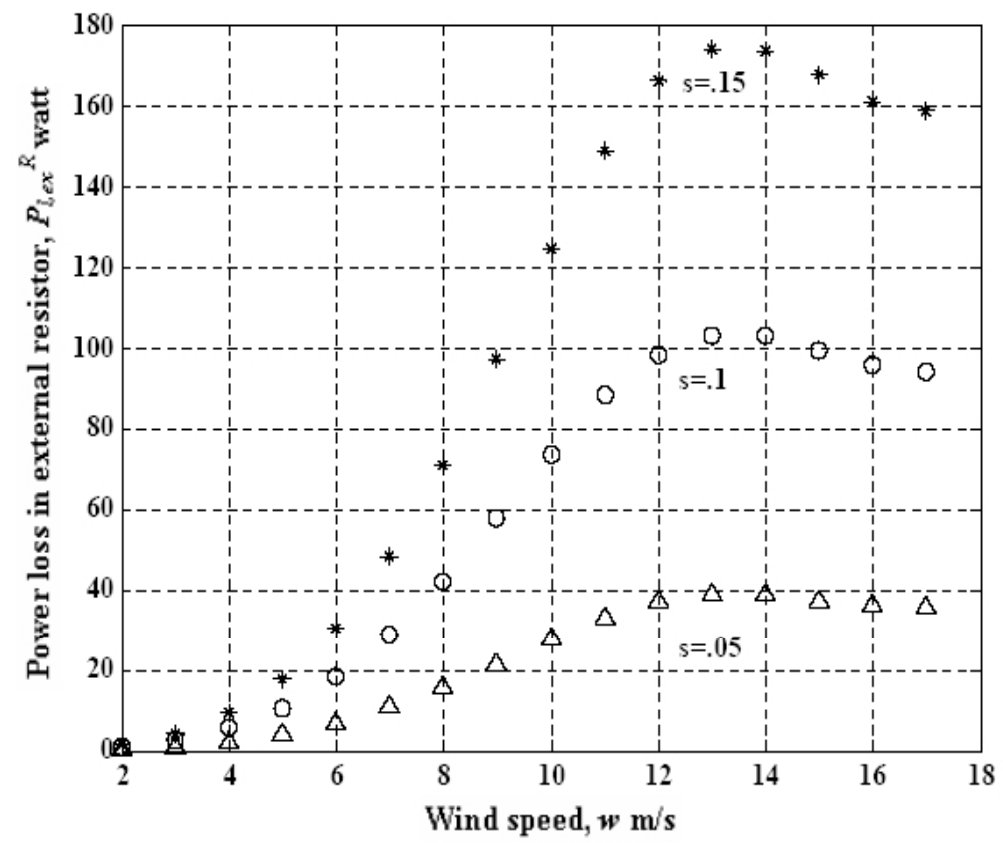

Fig. (9). External rotor resistance loss for a WRIG based system.

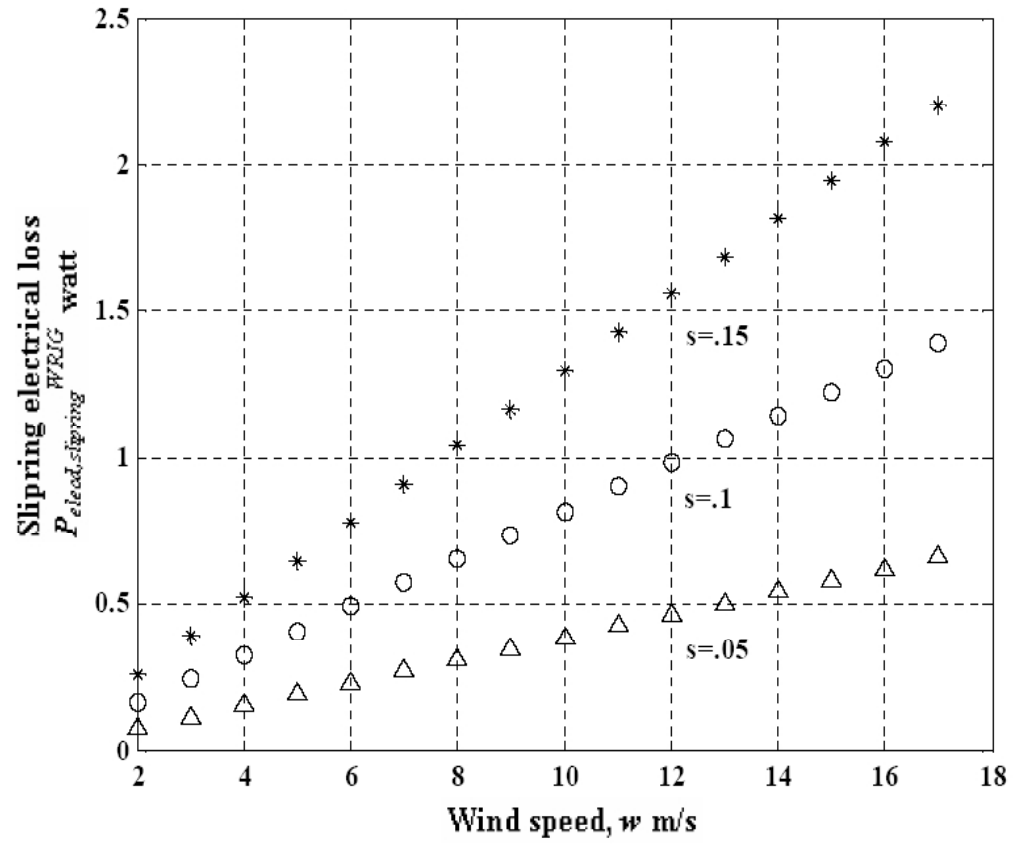

Fig. (10). Slip ring electrical loss for the WRIG based system.

cance as reaches close to the maximum speed while the voltage change has been considered linear from cut in to rated and rated to cut out wind speed. As a result, the captured aerodynamic power is asymmetrical on either side of the rated wind speed and consequently the current. The total conversion power losses from cut-in to cut-out wind speed for a PMG and WRIG based system is $374618 \mathrm{~W}$ and 301044 W respectively, while slip is limited to $15 \%$ for the WRIG based system. The result confirmed that with an upper limit of $15 \%$ of slip variation, a reduced power loss is possible by using the WRIG based system than a PMG based system. Fig. (14) depicts the efficiency of the power conditioning system for a PMG and WRIG based SWT system for a varying wind speed and slip. As shown in the graph, with the increase in slip, efficiency decreases for the WRIG based system over the PMG based system but remains high for the low wind regime $(2 \mathrm{~m} / \mathrm{s}$ to $11 \mathrm{~m} / \mathrm{s})$ and almost same for high wind regime $(11 \mathrm{~m} / \mathrm{s}$ to $17 \mathrm{~m} / \mathrm{s})$, while maintaining a slip of $15 \%$. The typical obstacle of a variable speed PMG based system is low efficiency at low wind speed that can be significantly improved using the WRIG based system. However, low efficiency at low wind speed for a SWT system is not desirable as SWT mostly faces low wind speed most of the time during the year $[25,26]$. Nonetheless, a higher effi- 


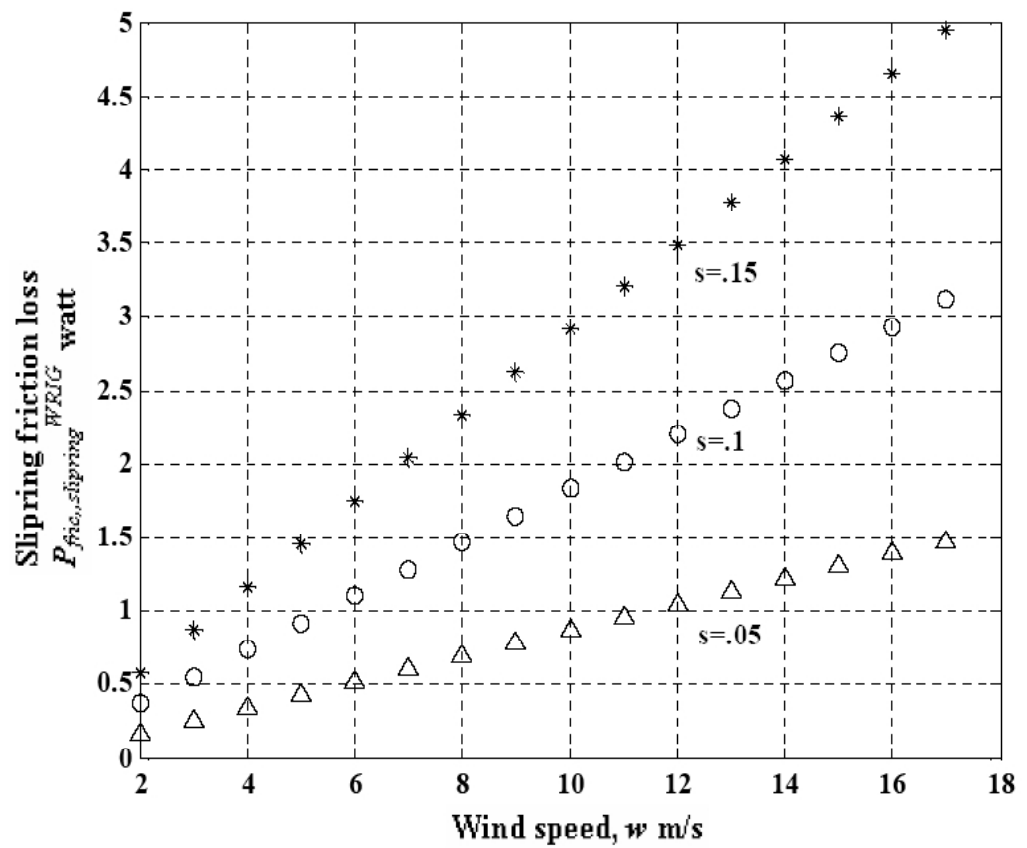

Fig. (11). Slip ring friction loss for the WRIG based system.

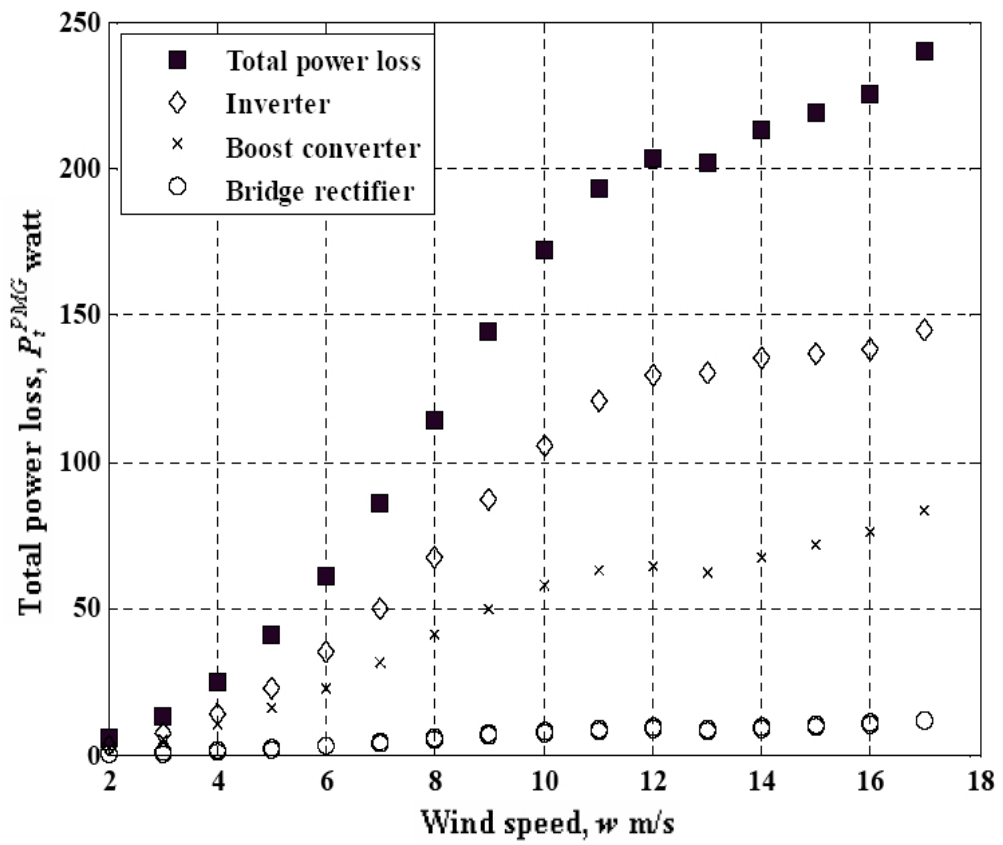

Fig. (12). Total loss for the PMG based SWT system as a variation of wind speed.

ciency of the PCS is achievable by changing the operating point, i.e., the switching frequency. The losses of power electronic components typically increase with an increase in switching frequency and subsequently decrease the efficiency leading to a less efficient system and vice versa. For low switching frequency, however, the ripple in the current is substantial, and there could be a considerable difference in turn-on and turn-off losses. A tradeoff should be made between the operating point of switching frequency and the desired performance of the system. An investigation is carried out in order to observe the dependency of the efficiency on switching frequency for the systems. Recall from section
4.1, a change in switching frequency changes the power loss in the PCS thus changes the efficiency. The efficiency of the PMG based system is subjected to switching frequency, while the WRIG based system is not as the loss analysis assumed that the chopper and external rotor resistance is on for the entire switching period. The variation of the switching frequency $(10 \mathrm{kHz}, 20 \mathrm{kHz}$ and $30 \mathrm{kHz})$ for the PMG based system is presented in the Fig. (15). At a lower switching frequency of $10 \mathrm{kHz}$, the efficiency of the PCS remains at $90 \%$. This is less than the efficiency typically claimed by manufacturers' for the PCS. It should be mentioned that efficiency claim by the manufacturers' are hard to rely on as the 


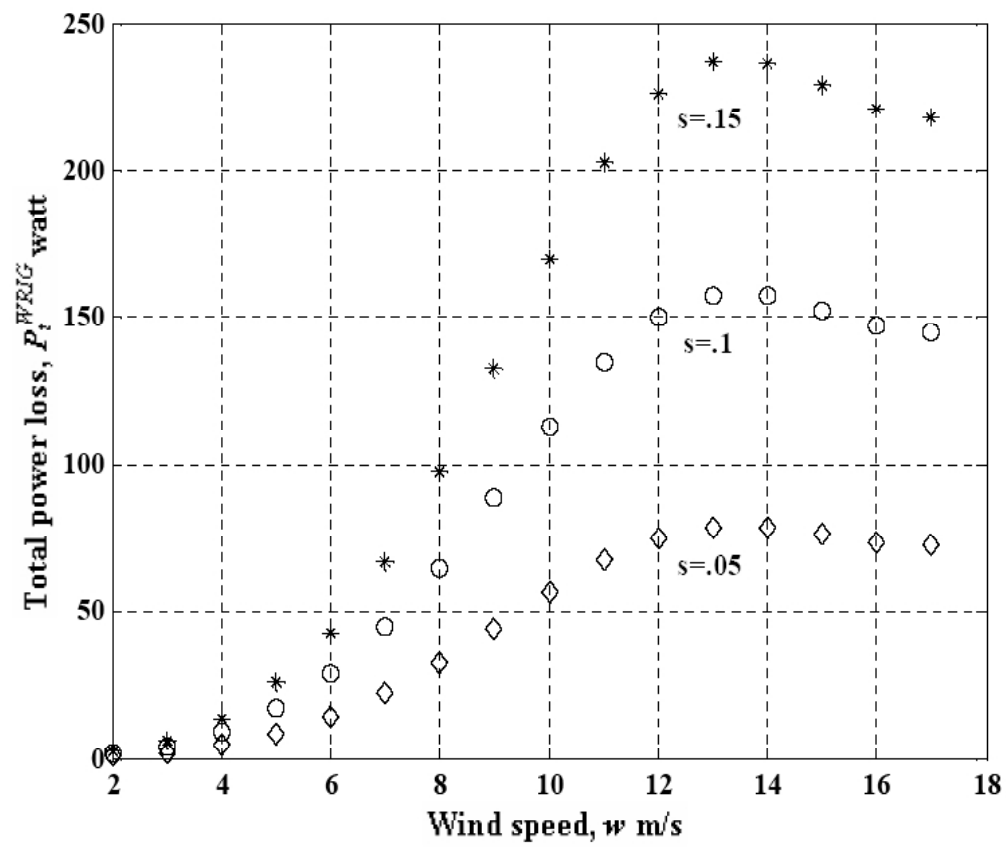

Fig. (13). Total loss for the PMG based SWT system as a variation of wind speed.

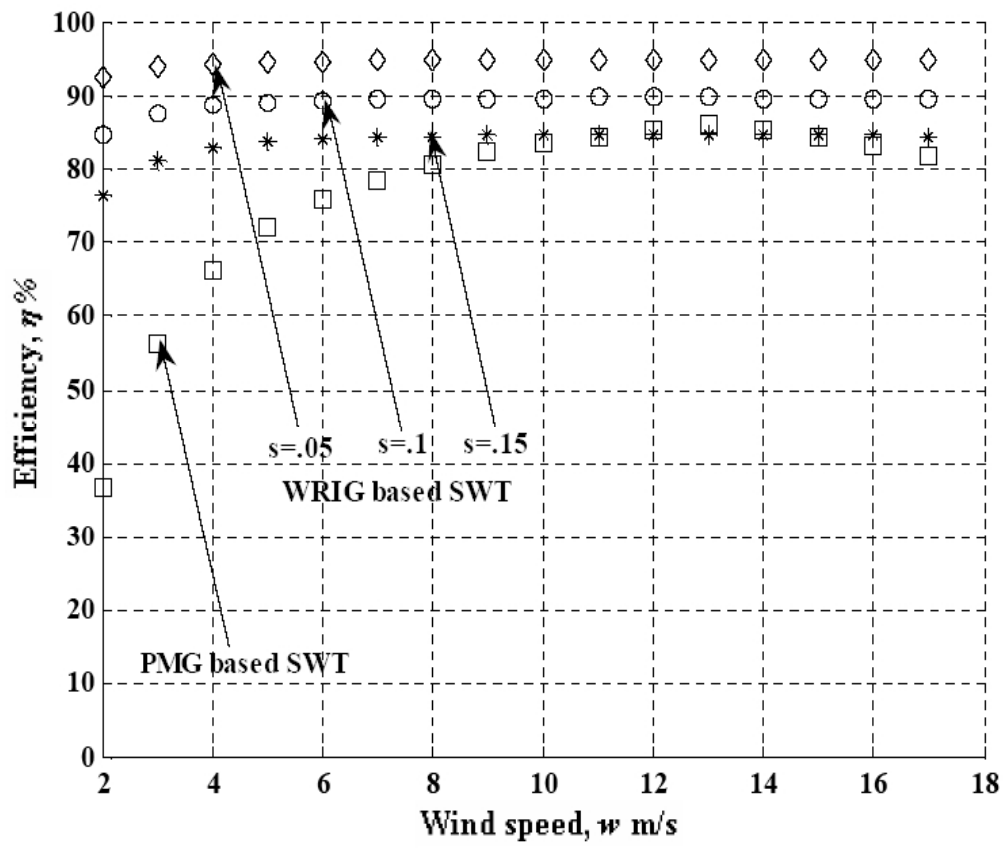

Fig. (14). Variation of efficiency with the change in wind speed for both systems.

actual operating condition remain unknown for most of the time. This is a major concern as users' typically shift for a system by assuming that the efficiency of the PCS will remain the same as claimed by the manufacturers' and which is not the factual scenario. For instance, Bergey wind power claimed the efficiency of the GridTek-10 inverter system is $92 \%$ [27], however, it has been reported by the NREL that the efficiency is about $86 \%$ over most of the operating region [28]. This research thus conclude that this inconsistency in the efficiency data mainly originate by the imperfect loss analysis while evaluating the efficiency of the PCS of a typi- cal PMG based small wind turbine. As a whole, the WRIG based system within a limited slip of $15 \%$ is capable of higher conversion efficiency. Power electronics in such systems will need a reduce cooling and it will simple and low cost. Furthermore, the WRIG based SWT system offers less complex control architecture to achieve a same control goal thus will lead to a higher reliability of the power electronics. It's worthwhile to mention that the PMG based system requires more complicated control and power drive circuitry consequently leading to more power losses and low reliability as compared to a WRIG based system. 


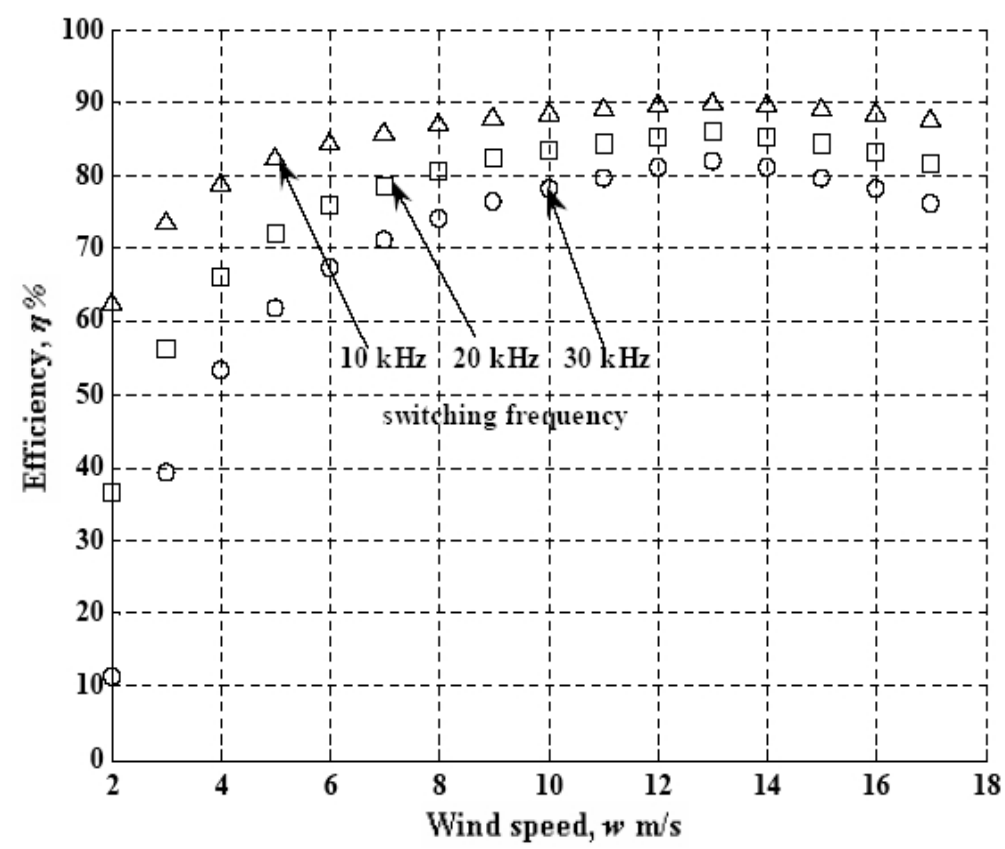

Fig. (15). Variation of efficiency with the change in switching frequency for the PMG based system.

\section{CONCLUSIONS}

The conversion losses analysis of the power conditioning system for a PMG and WRIG based SWT has been presented in this paper. The mathematical formulation of the PCS for both systems has been discussed with the operating conditions of the wind turbine. The efficiency of SWT systems for low wind speed is of importance but our loss analysis revealed that the PMG based system mainly dominates the efficiency at the high wind speed, while the WRIG based system provides high efficiency at low wind speed as well as high wind speed. This analysis also indicates that research on SWT should aim for a WRIG based system rather than the PMG based system in order to achieve low conversion losses, less complexity in power electronics, and high efficiency during the conversion.

\section{ACKNOWLEDGEMENT}

The authors' would like to thank the National Science and Engineering Research Council (NSERC) Canada for providing financial support of this research.

\section{NOMENCLATURE}

$$
\begin{aligned}
& E_{S R}, E_{\text {ON }}, E_{\text {OFF }}=\quad \begin{array}{l}
\text { Rated switching, on state and off state } \\
\text { loss energy respectively }
\end{array} \\
& f_{W T}, f_{S W}=\quad \begin{array}{l}
\text { Frequency of the wind turbine rotor and } \\
\text { switching frequency respectively }
\end{array} \\
& I_{d}, I_{o m}=\quad \begin{array}{l}
\text { Diode current and maximum amplitude } \\
\text { of the grid current respectively }
\end{array} \\
& I_{r e f, d}, I_{d c 1}=\quad \begin{array}{l}
\text { Reference and actual commutation cur- } \\
\text { rent respectively }
\end{array} \\
& I_{1}, I_{2}=\begin{array}{l}
\text { Stator and rotor current of the WRIG } \\
\text { based topology respectively }
\end{array}
\end{aligned}
$$

$\begin{array}{lll}R, R_{e} & = & \begin{array}{l}\text { Actual and effective resistance of the } \\ \text { rotor }\end{array} \\ r_{d}, r_{c e} & =\begin{array}{l}\text { On state resistance of the diode and } \\ \text { IGBT respectively }\end{array} \\ V_{f 0}, V_{c e 0}= & \begin{array}{l}\text { Diode and IGBT on state voltage drops } \\ \text { respectively }\end{array} \\ V_{r e f, d}, V_{r e f, I G B T}= & \begin{array}{l}\text { Reference commutation voltage of the } \\ \text { diode and IGBT respectively }\end{array} \\ V_{d c 1}, V_{d c 2}= & \begin{array}{l}\text { Actual commutation voltage of the rec- } \\ \text { tifier, boost converter and inverter re- } \\ \text { spectively }\end{array}\end{array}$

\section{REFERENCES}

[1] www.smallwinenergy.ca (accessed May 23, 2008).

[2] Shen, M.; Joseph, A.; Wang, J.; Peng, F.Z.; Adams, D.J. Comparison of traditional inverters and $\mathrm{Z}$-source inverter for fuel cell vehicles. IEEE Trans. Power Electron., 2007, 22(4), 1453-1463.

[3] Grauers, A. Efficiency of three wind energy generator systems. IEEE Trans Energy Convers., 1996, 11 (3), 650-657.

[4] Zitao, W.; Liuchen, C. PWM AC/DC Boost Converter System for Induction Generator in Variable-Speed Wind Turbines. In Canadian Conference of Electrical and Computer Engineering, Saskatoon, Saskatchewan Canada, May 1-4, 2005.

[5] Orlando, N.A.; Liserre, M.; Monopoli, V.G.; Mastromauro, R.A.; Dell'Aquila, A. Comparison of Power Converter Topologies for Permanent Magnet Small Wind Turbine System. In IEEE International Symposium on Industrial Electronics, Cambridge, UK, June 30-July 2, 2008

[6] Ohyama, K.; Arinaga, S.; Yamashita, Y. Modeling and Simulation of Variable Speed Wind Generator System Using Boost Converter of Permanent Magnet Synchronous Generator. In European Conference on Power Electronics and Applications, Aalborg, Denmark, September 2-5, 2007.

[7] Molina, M.G.; Mercado, P.E. A New Control Strategy of Variable Speed Wind Turbine Generator for Three-phase Grid-Connected 
Applications.In IEEE/PES Transmission and Distribution Conference and Exposition, Bogota, Colombia, August 13-15, 2008.

[8] Hoffmann, R.; Mutschler, P. The Influence of Control Strategies on the Energy Capture of Wind Turbines. In IEEE Industry Applications Conference, Rome, Italy, October 8-12, 2000.

[9] Polinder, H.; van der Pijl, F.F.A.; de Vilder, G.-J.; Tavner, P.J. Comparison of direct-drive and geared generator concepts for wind turbines. IEEE Trans. Energy Convers., 2006, 21(3), 725-733.

[10] Abrahamsen, F.; Blaabjerg, F.; Pedersen, J.K.; Thoegersen, P.B. Efficiency-optimized control of medium-size induction motor drives. IEEE Trans. Indust. Appl., 2001, 37(6), 1761-1767.

[11] Li, H.; Chen, Z. Design optimization and site matching of directdrive permanent magnet wind power generator systems. Renewable Energy, 2009, 34(4), 1175-1184.

[12] Qiao, Wei.; Zhou, Wei.; Aller, José M.; Harley, R.G. Wind speed estimation based sensorless output maximization control for a wind turbine driving a DFIG. IEEE Trans. Power Electron., 2008, 23(3), 1156-1169.

[13] Xiangjun, Z.; Zhe, C.; Blaabjerg, F. Design and Comparison of Full-size Converters for Large Variable-speed Wind Turbines. In European Conference on Power Electronics and Applications, Aalborg, Denmark, September 2-5, 2007.

[14] Chen, Z.; Spooner, E. Wind Turbine Power Converters: A Comparative Study. In International Conference on Power Electronics and Variable Speed Drives, London, UK, September 21-23, 1998.

[15] Blaabjerg, F.; Jaeger, U.; Munk-Nielsen, S. Power losses in PWMVSI inverter using NPT or PT IGBT devices. IEEE Trans. Power Electron., 1995, 10(3), 358-367.

[16] Helle, L.; Munk-Nielsen, S. Comparison of Converter Efficiency in Large Variable Speed Wind Turbines. In IEEE Applied Power Electronics Conference and Exposition, California, USA, March 4-8, 2001.

[17] Blaabjerg, F.; Pedersen, J.K.; Jaeger, U. Evaluation of Modern IGBT-Modules for Hard-Switched AC/DC/AC Converters. In IEEE Industry Applications Conference, Orlando, Florida, USA, October 8-12, 1995.

[18] Kimball, J.W.; Flowers, T.L.; Chapman, P.L. Low-input-voltage, low-power boost converter design Issues. IEEE Power Electron. Lett., 2004, 2(3), 96-99.
[19] Aghdam, M.G.H.; Gharehpetian, G.B. Modeling of Switching and Conduction Losses in Three-Phase SPWM VSC Using Switching Function Concept. In IEEE Power Tech 2005, St. Petersburg, Russia, June 27-30, 2005.

[20] Rivas, C.; Rufer, A. P.W.M. Current Converter for Electric Energy Production Systems From Fuel-Cells. In European Conference on Power Electronics and Applications, Graz, Austria, August 27-29, 2001.

[21] Jingquan, C.; Maksimovic, D.; Erickson, R. Buck-boost PWM Converters Having Two Independently Controlled Switches. In IEEE Power Electronics Specialists Conference, Orlando, Florida, USA, June 17-21, 2001.

[22] Arifujjaman, Md.; Iqbal, M.T.; Quaicoe, J.E. A Comprehensive Loss Calculation in Grid Connected Small Wind Turbine Systems, In $18^{\text {th }}$ Newfoundland Electrical and Computer Engineer Conference. St. John's, Newfoundland, November 6, 2008

[23] Mishra, A.K.; Wahi, A.K. Performance Analysis and Simulation of Inverter-fed Slip-power Recovery Drive. J. Inst. Eng. Part El Elect. Eng. Div., 2004, 85, 89-95.

[24] Nordlund, E.; Magnussen, F.; Bassilious, G.; Thelin, P. Testing of Silver- Copper- and Electro-Graphite Brush Materials for Slip Ring Units. Proceedings of Nordic Workshop on Power and Industrial Electronics, Trondheim, Norway, June 14-16, 2004.

[25] Erickson, Robert W. A Novel Power Electronics System for Wind Generation Applications. National Renewable Energy Laboratory (DOE), NREL/SR-500-33396, October 2004.

[26] Hong, H.; Liuchen, C. Energy Flow Principles of IGBT Inverters in Wind Energy Conversion System. In Canadian Conference on Electrical and Computer Engineering, Halifax, NS, Canada, March 7$10,2000$.

[27] www.bergey.com (accessed January 28, 2009).

[28] Jeroen van, D.; Mark, M. Wind Turbine Generator System Power Performance Test Report for the Bergey Excel-S/60 Wind Turbine with SH3052 Airfoil Blades in Golden, Colorado. National Renewable Energy Laboratory (DOE), NREL/EL-500-33452, April 2003.

(C) Arifujjaman et al.; Licensee Bentham Open.

This is an open access article licensed under the terms of the Creative Commons Attribution Non-Commercial License (http://creativecommons.org/licenses/by-nc/3.0/) which permits unrestricted, non-commercial use, distribution and reproduction in any medium, provided the work is properly cited. 